\title{
Abrupt changes in regional temperature in the conterminous United States, 1895-1989
}

\author{
Tsuneharu Yonetani ${ }^{1}$, Gregory J. McCabe, $\mathrm{Jr}^{2}$ \\ ${ }^{1}$ National Research Institute for Earth Science and Disaster Prevention, Science and Technology Agency, Tennodai 3-1, \\ Tsukuba, Ibaraki 305, Japan \\ ${ }^{2}$ U.S. Geological Survey, Denver Federal Center, MS 412, Lakewood, Colorado 80225, USA
}

\begin{abstract}
In this study, the Lepage test, a nonparametric 2-sample test, was used to statistically analyze annual and seasonal temperatures for the 344 climate divisions in the conterminous United States for the years 1895 through 1989. The objectives of the study were to (1) identify statistically significant changes in annual and seasonal temperatures, (2) determine during which seasons the most dramatic changes in temperature occurred, (3) determine the spatial distribution of significant changes in temperature, and (4) determine whether significant regional temperature changes represented gradual or abrupt changes. The analysis indicated that abrupt and significant changes in annual and seasonal temperatures occurred near 1930 and 1958, and that these changes occurred over large parts of the conterminous United States. Other significant and abrupt changes in seasonal temperatures occurred during the summer near 1917 and 1943, and during the autumn near 1948 and 1964. Temperatures during the summer season exhibited the most frequent and widespread significant changes. The results of this study suggest that significant changes in regional temperature occur abruptly, as opposed to gradual uniform changes. In addition, the changes in temperature were spatially extensive and appear to be associated with changes in atmospheric circulation.
\end{abstract}

KEY WORDS: Temperature change - Lepage test - United States - Climatic change

\section{INTRODUCTION}

General circulation models (GCMs) are mathematical representations of the Earth's climate system. In recent years, GCMs have been used to evaluate the effects of increasing atmospheric concentrations of 'greenhouse' gases, such as carbon dioxide $\left(\mathrm{CO}_{2}\right)$, on global and regional climates. There is concern that increasing atmospheric concentrations of 'greenhouse' gases will cause global and regional climate changes that will include increases in temperature and changes in temporal and spatial distributions of precipitation (Lins et al. 1988, Schlesinger 1989).

There have been numerous studies of changes and trends in temperature in the Northern Hemisphere and in the conterminous United States (Kalnicky 1974, Diaz \& Quayle 1980, Jones et al. 1982, 1986, Karl \& Riebsame 1984, Kalnicky 1987). Diaz \& Quayle (1980) found 3 periods of temperature regimes that occurred in the conterminous United States during the period 1895 through 1977 (1895-1920, 1921-1954, and
1955-1977). In addition, Diaz \& Quayle found that temperatures in the western and eastern halves of the United States fluctuated out of phase with each other. Karl \& Riebsame (1984), in a study of seasonal and annual temperatures in the conterminous United States, found 1 - to 2-decade fluctuations in temperature for many regions of the country. Karl \& Riebsame also found that the largest fluctuations occurred during the summer season.

Because the primary effect of increased atmospheric concentrations of 'greenhouse' gases is believed to be global warming, temperature records have been analyzed to identify trends in temperature. Recent studies of trends in global temperature suggest an increase in global annual mean temperature of 0.3 to $0.6^{\circ} \mathrm{C}$ over the past century (Intergovernmental Panel on Climate Change 1990,1992). On a regional scale, however, this trend is not consistent or even apparent for many regions of the world (Diaz \& Quayle 1980, McGuirk 1982, Pittock 1983, Karl \& Riebsame 1984, Yamamoto et al. 1986, Balling \& Idso 1989, Yonetani 1992). The 
methods used to evaluate trends in temperature, resulting from increasing atmospheric concentrations of greenhouse gases, generally assume that changes in temperature are linear through time (Balling \& Idso 1989, Plantico et al. 1990). In addition, many studies of the effects of hypothetical climatic changes employ gradual linear changes in climate (Gleick 1987. McCabe \& Wolock 1992). This assumption of a linear trend is rather restrictive (Solow \& Broadus 1989). In contrast, the results of studies by Diaz \& Quayle (1980) and Karl \& Riebsame (1984) suggest that temperature changes in an abrupt manner from one regime to another. Similarly, Lorenz $(1968,1976)$ suggests that the climate system is a nonlinear chaotic system and that climate changes in a step-like fashion. Thus, statistics of climatic conditions for many regions may differ markedly for various finite intervals.

To properly simulate climatic change and evaluate the effects of such changes, an understanding of the manner in which climate has changed in the past is necessary. The objectives of this study are to evaluate seasonal and annual temperatures in the conterminous United States for the period 1895 to 1989 to (1) identify statistically significant changes in seasonal and annual temperatures that occurred during the study period, (2) determine during which seasons the most dramatic changes in regional temperature have occurred, (3) determine the spatial distribution of significant changes in temperature, and (4) determine if the significant changes in regional temperature in the conterminous United States were gradual or abrupt changes.

\section{METHODS}

Data used for this analysis included monthly mean temperatures for the $344 \mathrm{cli}$ mate divisions in the conterminous United States for the period January 1895 through August 1989 (data were obtained from the National Climatic Data Center, Asheville, North Carolina) (Fig. 1). The climate divisions represent regions within states that are, as nearly as possible, climatically homogeneous (Karl \& Riebsame 1984). In addition, the data for the climate divisions have been corrected for time-of-observation bias (Karl et al. 1986). Although extreme climatic variations can occur in areas of complex terrain, such as the mountainous areas of the western United States, standardized departures of temperature from normal are spatially consistent within a climate division (Karl \& Riebsame 1984). Karl \& Riebsame (1984) identified fluctua- tions in seasonal and annual temperatures over the period 1931 through 1982 and found that significant temperature fluctuations occurred over large regions, indicating a large amount of spatial coherence in temperature anomalies. Karl \& Riebsame concluded that significant temperature fluctuations span several climate divisions or even several states. Because of the large spatial coherence of temperature fluctuations, temperature data from climate divisions are adequate for analyzing changes in regional temperature. In addition, this paper addresses changes in temperature between consecutive multi-year periods. At this temporal scale, temperature variations at individual stations are highly correlated with temperature values at their respective climate divisions (Karl \& Riebsame 1989). Even in the mountainous areas of the western United States, station temperature values are highly correlated with climate division temperature values.

The monthly mean temperature values were averaged to produce seasonal and annual mean temperature values. The winter season was represented by data for December, January and February, the spring season by March, April and May, the summer season by June, July and August, and the autumn by September, October and November.

Several statistical tests have been used to detect changes in temperature and precipitation, such as the bivariate test (Potter 1981), Pettitt's change point test (Demaree \& Nicolis 1990), and the application of the 2phase regression model (Solow 1987). These tests are associated with various underlying assumptions and limitations. The most common limitation among many of these approaches is the assumption of a single change in the time series analyzed (Solow 1987).

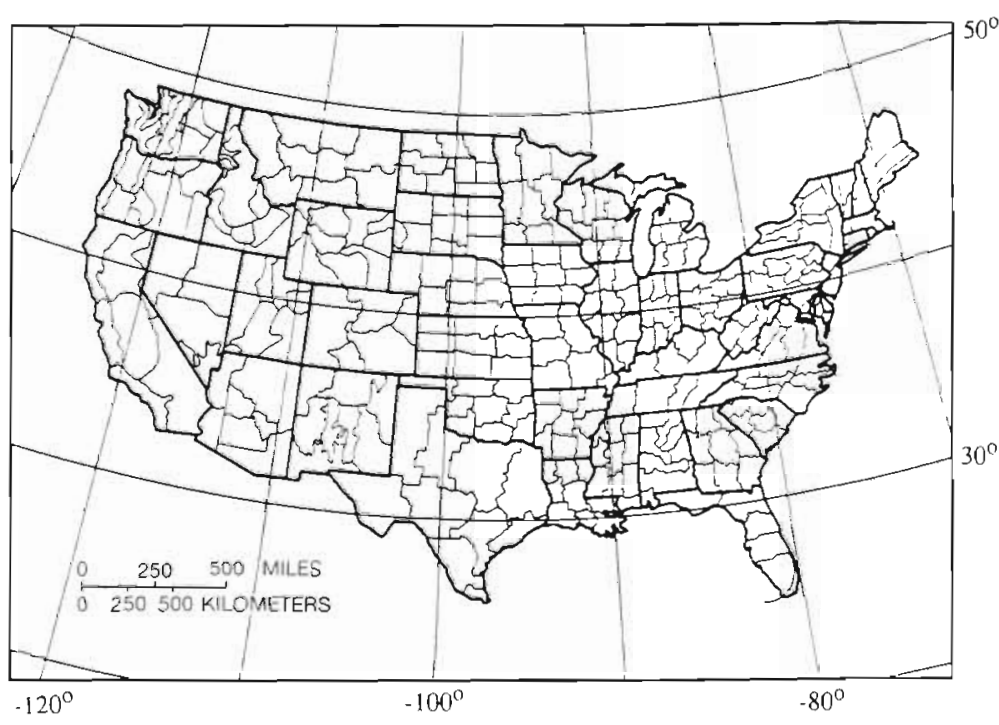

Fig. 1 National Climatic Data Center climate divisions for the conterminous United States 
In this study, the seasonal and annual temperature values were evaluated for statistically significant changes by using the Lepage test statistic (Lepage 1971). The Lepage test statistic $(H K)$ is a nonparametric 2-sample test that tests for significant differences between 2 samples, even if the distributions of the parent populations are unknown. The Lepage test can detect changes in the mean and in the variance of a variable through time. Also, because the Lepage test is a nonparametric test it is not sensitive to isolated extremes. The Lepage test has few underlying assumptions and can be used to detect a variety of types of changes in climatic time series including linear trends, cyclical variations, and step-like changes (Yonetani 1993). In addition, the Lepage test has been shown to be more statistically powerful than other similar tests, such as the Wilcoxon-Mann-Whitney test, the Student $t$-test, the Ansari-Bradley test, the Kolmogorov-Smirnov test, the Kuiper test, and the Chisquare test (Hirakawa 1974). The Lepage test statistic is calculated by Eq. (1).

Intervals of data along a single time series are compared in the following manner: data for $N$ years previous to a specified year $Y_{C}$ (sample a) are compared to data for year $Y_{C}$ plus the $N-1$ years following year $Y_{C}$ (sample b). The Lepage test is used to determine if the 2 samples are statistically different at a specified significance level (i.e. at alpha $=0.01$ or 0.05 ). The year $Y C$ is moved successively at 1 yr increments along the time series and the Lepage test is conducted for each year $Y_{C}$. For this study, distributions of seasonal and annual temperatures for periods $(N)$ of $10,15,20$ and $25 \mathrm{yr}$ were compared. The lowest value, $10 \mathrm{yr}$, was used to test decadal changes such as those identified by Karl \& Riebsame (1984, 1989), and the maximum value, $25 \mathrm{yr}$, was used to identify quarter-century changes such as those discussed by Ghil \& Vautard (1991) and Dettinger \& Ghil (1992). The Lepage test was performed by using seasonal and annual temperature data for each of the 344 climate divisions in the conterminous United States. For each year $Y_{C}$ and Nvalue, the num- ber of climate divisions indicating a significant change in temperature was calculated.

\section{RESULTS}

\section{Changes in annual and seasonal temperature}

Fig. 2 illustrates the number of climate divisions with significant changes (at alpha $=0.01$ ) in annual mean temperature for each year $Y_{C}$ and for each $N$ value used in this study. For all $N$ values, a significant change in temperature occurred at many climate divisions around 1958 (i.e. from the mid-1950s to the mid1960s, hereafter referred to as near 1958). That is, near 1958, the Lepage tests for at least 100 climate divisions indicate significant differences in temperature between the $N$ years previous to 1958 and the years 1958 plus the $N-1$ subsequent years. For all $N$ values, the number of climate divisions where the test statistic indicates significant changes in temperature also is large near 1921, and from the mid-1920s to the mid1930s (hereafter referred to as near 1930). Near 1911, significant changes in temperature at a small number of climate divisions are indicated.

The changes in temperature illustrated in Fig. 2 suggest that some of the changes may be abrupt changes in temperatures for many of the climate divisions, especially near 1958. If changes in annual mean temperatures were linear over the period of study, peaks at these specific years would not occur because the changes would be gradual and consistent over the study period. In addition, if the changes in temperature were random events, then a large number of climate divisions would most likely not indicate statistically significant changes during the same periods of time.

There are many factors that influence the homogeneity of climatic time series, such as changes in observation practices, and changes in the number and spatial distribution of stations. Inhomogeneities in temperature records caused by such changes are different

Equation (1). Calculation of the Lepage test statistic (HK)

$$
H K=\frac{\left[\sum_{i=1}^{2 n} i \cdot u_{i}-\frac{1}{2} n_{1}(2 n+1)\right]^{2}}{\frac{1}{12} n_{1} n_{2}(2 n+1)}+\frac{\left[\sum_{i=1}^{n} i \cdot u_{1}+\sum_{i=n+1}^{2 n}(2 n-i+1) u_{i}-\frac{1}{4} n_{1}(2 n+2)\right]^{2}}{\frac{n_{1} n_{2}(2 n-2)(2 n+2)}{48(2 n-1)}}
$$

where $n_{1}$ and $n_{2}$ are sample sizes of samples $a$ and $b$ respectively; $2 n=n_{1}+n_{2} ; u_{4}=1$ when the $i$ th record in a combined sample of ranked values of samples $a$ and $b$ belongs to the sample $a_{1}$ and $u_{1}=0$ when it belongs to the sample $b$. When $H K$ exceeds 9.210, the samples $a$ and $b$ are statistically different at the alpha $=0.01$ level, and when HK exceeds 5.991, the samples are statistically different at the alpha $=0.05$ level. 


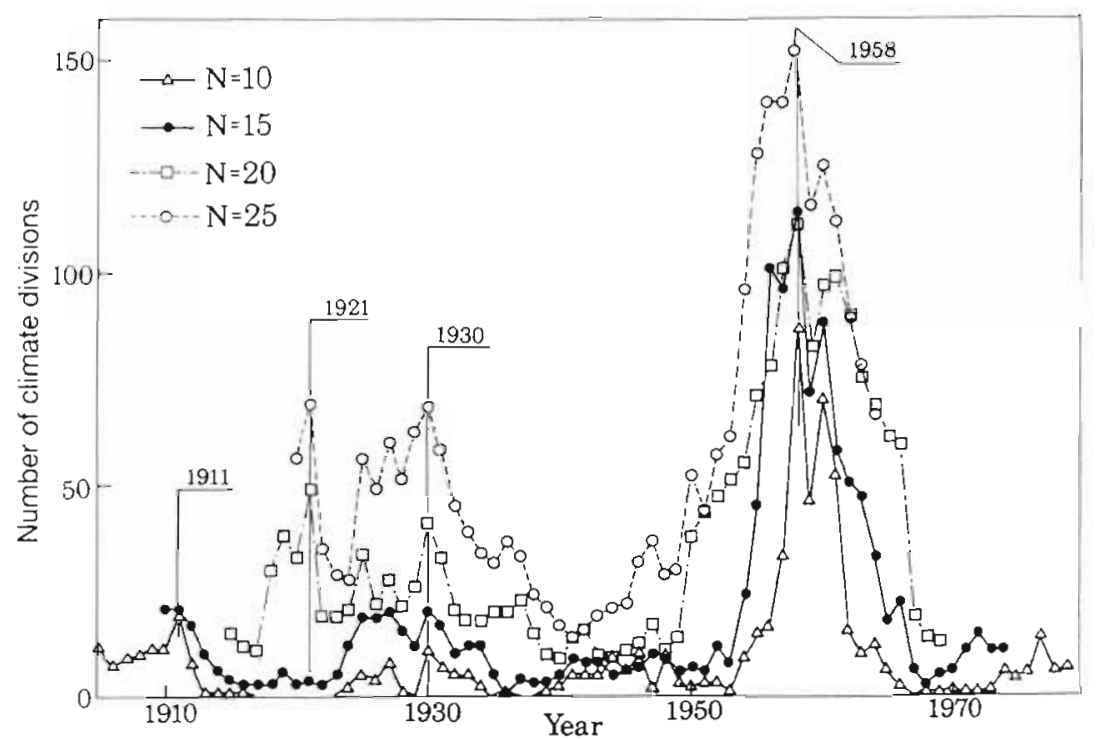

Fig. 2. Number of climate divisions indicating significant changes in annual mean temperatures at alpha $=0.01$

among the climate divisions. The changes in temperature indicated in this paper are systematic in space and time. It is unlikely for these results to be explained by biases in the records caused by changes in observation practices. Thus, the changes presented are considered to be real.

Changes in seasonal temperatures also were tested in the same manner as were the annual temperatures, and similar results were obtained; i.e. the time variations of the number of climate divisions with significant changes in temperature indicated abrupt changes of seasonal temperatures at a regional scale. Through analysis of annual and seasonal temperatures using the Lepage test, and by examining time series of annual and seasonal temperature at all climate divisions it was determined that an $N$ value of 15 was the most appropriate for detecting changes in seasonal and annual temperature the $N$ value of 15 is close to the $N$ values used by Karl \& Riebsame (1984)].

Fig. 3 illustrates the number of climate divisions indicating significant changes (at alpha $=0.01 \mathrm{f}$ in seasonal temperatures for $N=15$. The results of the seasonal analysis indicate that summer temperatures experienced the most frequent significant changes during the study period. Changes in summer temperatures for a large number of climate divisions occurred near 1917. 1930, 1943, and from the mid-1950s through the mid-1960s (with a peak at 1958). Significant changes in winter tem- peratures at a large number of climate divisions only occurred once, near 1958 (i.e. from the mid-1950s to the mid-1960s). Significant changes in autumn temperatures at a large number of climate divisions only occurred twice, near 1948, and near 1964. Significant changes in spring temperatures are never indicated for more than 13 climate divisions. Because temperature changes near 1930 and 1958 are the most significant in both the annual and seasonal analyses, changes during these periods were the primary focus of the remainder of the study.

The results illustrated in Figs. 2 \& 3 indicate periods when significant changes in temperature at a large number of climate divisions occurred. These figures do not, however, indicate the direction or spatial distribution of these changes. To evaluate the direction and spatial distribution of the changes illustrated by Figs. 2 $\& 3$, maps were made indicating the direction of changes in temperature and the location of the climate divisions indicating significant differences in temperature (at alpha $=0.05$ and 0.01 ) between the $15 \mathrm{yr}$ period before year $Y_{C}$ and the $15 \mathrm{yr}$ period that includes $Y_{C}$ and the $N-1$ subsequent years. Maps were made for annual and summer temperature changes for 1930 (Fig. 4), and for annual, winter, and summer temperature changes for 1958 (Fig. 5).

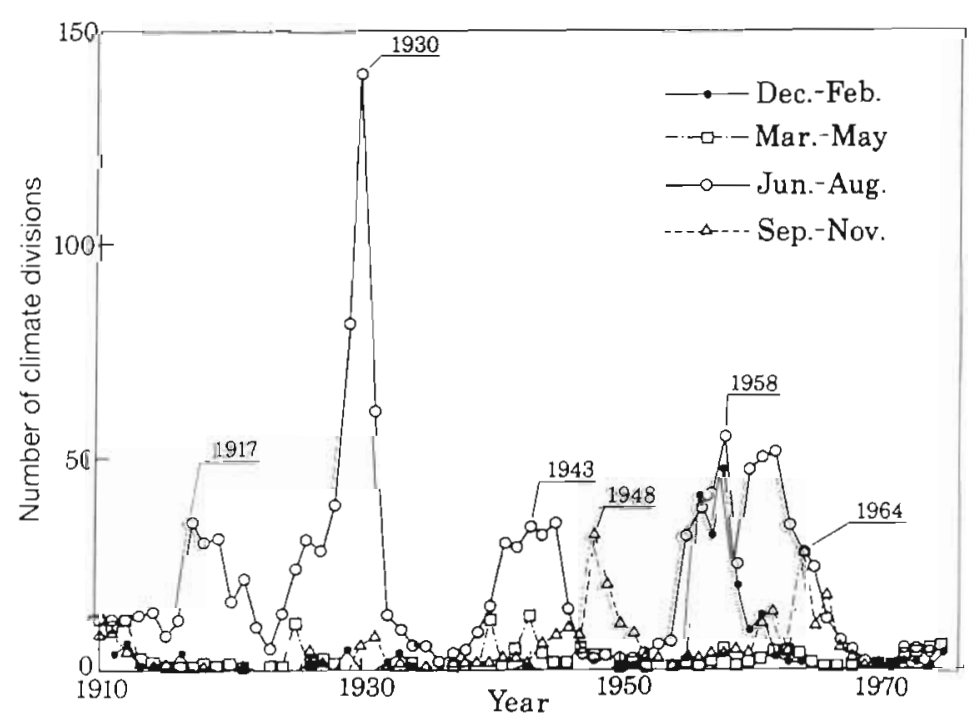

Fig. 3. Number of climate divisions indicating significant changes in seasonal mean temperatures at alpha $=0.01$ 
The map indicating the spatial distribution of summer temperature changes for YC near 1930 indicates that 139 climate divisions experienced positive changes in temperature significant at alpha $=0.01$ (Fig. 4B). The majority of the climate divisions indicating significant changes in temperature are located in the north-central and northeastern United States. In the north-central United States summer temperatures increased by more than $1.5^{\circ} \mathrm{C}$. In addition to the climate divisions that indicated significant increases in temperature at alpha $=0.01$ (large black dots), several other stations experienced significant increases in temperature at alpha $=0,05$ (black triangles). These results for the summer temperatures near 1930 are consistent with the occurrence of the 'dust bowl' years during the late 1920 s and the early to mid1930s (Namias 1983). The increase in summer temperatures near 1930 had a significant effect on annual temperatures, as shown by the map indicating the spatial distribution of the Lepage test results for annual temperatures near 1930 (Fig. 4A), and the peak near 1930 indicated in Fig. 2.

In contrast to 1930 , the majority of the significant changes in temperature near 1958 indicated by winter, summer, and annual temperatures, are decreases in temperatures from before 1958 to after 1958. The number of climate divisions indicating significant changes in annual temperatures at alpha = 0.01 near 1958 is 114 (112 climate divisions indicated decreases in annual temperature). Of these, 47 climate divisions indicated significant changes in winter temperatures near 1958 at alpha $=0.01$ (all 47 climate divisions indicated decreases in winter temperatures), and 55 climate divisions experienced significant changes in summer temperatures near 1958 at alpha $=0.01$ (38 of the 55 climate divisions indicated decreases in summer temperatures). An examination of Fig. 5 shows that the significant changes in temperatures were primarily decreases in temperature and that the changes generally occurred in the eastern United States. The greatest decreases, however, occurred during the winter season, with decreases exceeding $1.5^{\circ} \mathrm{C}$ at more than half of the climate divisions, and decreases exceeding $2^{\circ} \mathrm{C}$ at 23 climate divisions. Fig. $5 \mathrm{C}$ illustrates significant decreases in summer temperatures near 1958 for 38 climate divisions in the eastern part of the United States, but also indicated are some significant increases in summer temperatures near 1958 in the western
United States (at 17 climate divisions), especially in the northwestern United States.

\section{Other abrupt changes in seasonal temperature}

Although the remainder of this paper primarily focuses on changes in temperature near 1930 and 1958 , it is interesting to examine the direction and spatial distribution of changes in temperature for other periods when the Lepage test indicated significant changes in temperature at a relatively large number of climate divisions (Fig. 3). Fig. 6 illustrates the direction and spatial distribution of significant changes in seasonal tempera-
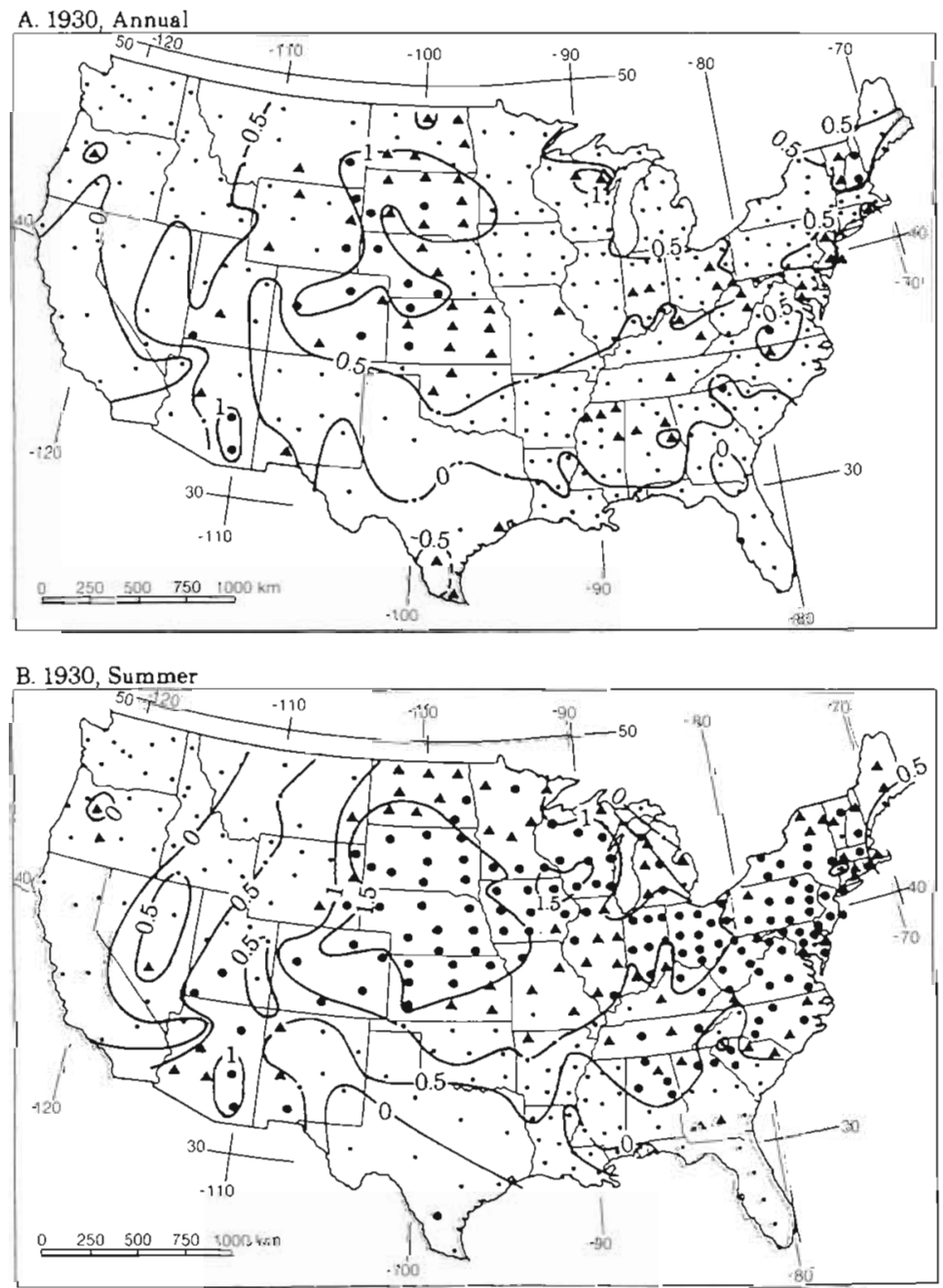

Fig. 4. Changes (in ${ }^{\circ} \mathrm{C}$ ) in (A) annual mean temperatures, and (B) summer mean temperatures, for the Lepage test conducted for 1930. (•) Climate divisions indicating a change in temperature significant at alpha $=$ 0.01; ( $\mathbf{1}$ ) climate divisions indicating a change in temperature significant at alpha $=0.05$; contour interval $=0.5^{\circ} \mathrm{C}$; temperature increases are indicated by solid contours and temperature decreases are indicated by dashed contours 



Fig. 5. Changes $\left(\mathrm{m}{ }^{\circ} \mathrm{C}\right)$ in (A) annual mean temperatures, (B) winter mean temperatures, and (C) summer mean temperatures for the Lepage test conducted for 1958. (-) Climate divisions indicating a change in temperature significant at alpha $=0.01 ;(\mathbf{\Delta})$ climate divisions indicating a change in temperature significant at alpha $=0.05$; contour interval $=$ $0.5^{\circ} \mathrm{C}$ temperature increases are indicated by solid contours and temperature decreases are indicated by dashed contours tures for 4 of the other periods identified in Fig. 3. Near 1917, summer temperatures dramatically increased, by as much as $2^{\circ} \mathrm{C}$ at many locations in the central and northern parts of the western United States. Increases in summer temperatures of more than $1.5^{\circ} \mathrm{C}$ occurred at 5 climate divisions. In contrast, summer temperatures decreased in the northern part of the western United States near 1943. However, the area affected was much smaller than the area affected by the changes near 1917. Significant changes in autumn temperatures occurred at a large number of climate divisions near the years 1948 and 1964. Near 1948 autumn temperatures significantly decreased in the southeastern United States, and near 1964 autumn temperatures significantly decreased in the northcentral United States and in parts of the northeastern United States. Similar to the spatial distributions of changes in temperature illustrated in Figs. 4 \& 5, there is a large amount of spatial coherence in the spatial distributions of changes in temperature illustrated in Fig. 6. In addition, examination of Figs. 4 through 6 indicates that significant changes in temperature occurred 2 to 3 times at some climate divisions, especially during the summer season.

\section{DISCUSSION}

The Lepage test statistically shows that annual and seasonal temperatures abruptly changed in the conterminous United States several times during the period 1895 through 1989. In addition, the significant changes in temperature occurred over large areas. The periods of changes in temperature identified in this study are similar to changes identified in other studies. In this study, a large number of climate divisions experienced significant increases in annual and summer temperature near 1930 and significant decreases in winter, summer, and annual temperatures near 1958. Diaz \& Quayle (1980) divided the mean temperature record for the United States into 3 time periods based on differences in temperatures; $1895-1920,1921-1954$ and 1955-1977. Near 1921, Diaz \& Quayle found increases in annual temperatures in the central and eastern United States, increases in summer temperatures in the central United States, and increases in winter temperatures 



Fig. 6. Changes (in ${ }^{\circ} \mathrm{C}$ ) in (A) summer mean temperatures near 1917, (B) summer mean temperatures near 1943, (C) autumn mean temperatures near 1948, and (D) autumn mean temperatures near 1964. (•) Climate divisions indicating a change in temperature significant at alpha $=0.01 ;(\boldsymbol{\Lambda})$ climate divisions indicating a change in temperature significant at alpha $=0.05$; contour interval $=$

$0.5^{\circ} \mathrm{C}$ i temperature increases are indicated by solid contours and temperature decreases are indicated by dashed contours

in the eastern United States. Near 1955, Diaz \& Quayle found decreases in annual, winter, and summer temperatures in the eastern United States. These results are similar to those found in this study. In addition, the breaks between the 3 time periods identified by Diaz \& Quayle (1921 and 1955) are similar to the periods of change identified in this study (early 1920s to mid1930s and 1958).

Karl \& Riebsame (1984) found a significant change in winter and summer temperatures in the conterminous United States during the mid-1950s. They found significant decreases in temperatures in the eastern half of the United States and a significant increase in temperature in the western United States. These results are consistent with the results of the Diaz \& Quayle study (1980), and with the results of this study. Another similarity between the study by Karl \& Riebsame (1984) and the results of this study is that the largest and most widespread significant changes in temperature occurred during the summer season.
Kalnicky $(1974,1987)$ also discusses 3 distinct temperature episodes in the conterminous United States; a cool period prior to the 1920s, a warm period from the 1920 s to the mid-1950s, and a cool period after the mid1950s. These divisions in temperature regimes also are consistent with those identified in this study.

\section{Causes of the regional changes in temperature}

Kalnicky (1974, 1987), van Loon \& Williams (1976) and Skeeter \& Parker (1985) demonstrated that regional temperature trends at the surface are related to changes in atmospheric circulation. Skeeter \& Parker (1985) state that temperature trends in the conterminous United States are highly dependent on variations in upper atmospheric circulation over North America between zonal and meridional flow conditions. The temperature changes near 1930 and 1958 indicated by this study can be explained, in part, by 
changes in atmospheric circulation. The peak near 1930 indicates the occurrence of the warm summers during the late 1920s and early to mid-1930s. Anomalous anticyclonic circulation dominated the central United States during this period, resulting in compressional heating of the air and subsequently producing above-average temperatures over a large portion of the United States (Namias 1983).

The temperature change near 1958 is indicated for winter, summer, and annual temperatures, and is primarily found in the climate divisions of the eastern United States. Similar to the results for 1930, these results can be explained, in part, by changes in atmospheric circulation. The Pacific North American (PNA) index is a useful index of large-scale atmospheric circulation over North America, especially during winter (Wallace \& Gutzler 1981, Yarnal \& Diaz 1986, Yarnal \& Leathers 1988), and has been recognized as a primary mode of atmospheric circulation variability over North America (Simmons et al. 1983, Barnston \& Livezy 1987. Leathers et al. 1991, Leathers \& Palecki 1992). Even during times of the year when the PNA pattern is not a major mode of atmospheric variability, the PNA index is a rough measure of the relative amplitude of the stationary waves over the North American continent (Leathers et al. 1991, Leathers \& Palecki 1992). In addition, the PNA index has been found to be highly correlated with surface temperatures for many spatiallycoherent regions of the United States (Leathers et al. 1991, Leathers \& Palecki 1992) and has proven to be a valuable aid in better understanding climatic changes on time scales ranging from months to decades and at spatial scales from climate divisions to hemispheric scales (Leathers \& Palecki 1992).

The mean atmospheric circulation over the Pacific/ North American region is characterized by a trough in the east-central North Pacific Ocean, a ridge over the Rocky Mountains, and a trough over eastern North America (Fig. 7). The PNA index represents departures from this mean circulation. It is best represented by geopotential height data from the mid- to upper troposphere because the elevated landmass of the Rocky Mountains interferes with the coherency of the pressure and geopotential height fields at lower elevations (Blackmon et al. 1984).

A measure of the relative strength of the PNA pattern can be constructed by a linear combination of standardized $700 \mathrm{mb}$ height anomalies $\left(Z_{i}\right)$ at the anomaly centers discussed above (Wallace \& Gutzler 1981). The PNA index was given in Yarnal \& Diaz (1986) as

$$
P N A=\frac{1}{3}\left[-Z_{1}+Z_{2}-Z_{3}\right]
$$

where $Z_{1}$ is the standardized $700 \mathrm{mb}$ height anomaly for $47.9^{\circ} \mathrm{N}, 170.0^{\circ} \mathrm{W} ; Z_{2}$ is the anomaly at $49.0^{\circ} \mathrm{N}$, $111.0^{\circ} \mathrm{W}$ and $Z_{3}$ is the anomaly at $29.7^{\circ} \mathrm{N}, 86.3^{\circ} \mathrm{W}$. This index differs from the index of Wallace \& Gutzler (1981), which included $700 \mathrm{mb}$ height anomalies for an area in the subtropics of the North Pacific Ocean. This center is omitted in this form of the index to focus on the atmospheric circulation affecting North America. This form of the PNA index is constructed so that positive values indicate meridional atmospheric flow over North America, and negative values indicate zonal atmospheric flow across North America (Fig. 7).

Examination of a time series of PNA values for the winter and summer seasons indicates a shift in largescale atmospheric circulation before and after 1958 during the winter and summer (Fig. 8). The time series of winter and summer PNA values indicate that before 1958 the summer and winter mean atmospheric circulations were dominated by negative PNA patterns with generally zonal atmospheric flow over North America. This pattern results in below-average temperatures in the western United States and above-average temperatures in the eastern United States. In contrast, for the period after 1958, the PNA index was primarily positive indicating a stronger-than-normal ridge of high pressure over the western United States and an enhanced trough over the eastern United States. This situation generally produces above-average temperatures in the western United States and below-average temperatures in the eastern United States. The winter and summer maps indicating the climate divisions experiencing significant changes in winter and summer temperatures near 1958 indicate that the majority of the significant changes occurred in the eastern United States and that these changes were decreases in temperature. These results are consistent with changes in the PNA pattern observed from before 1958 to after 1958.



Fig. 7. Character of atmospheric flow at the $700 \mathrm{mb}$ level for mean (thick black line), positive (thick gray line), and negative (dashed line) values of the Pacific North American (PNA) index. Positive values of the PNA index indicate enhanced meridional flow, and negative values indicate zonal flow 

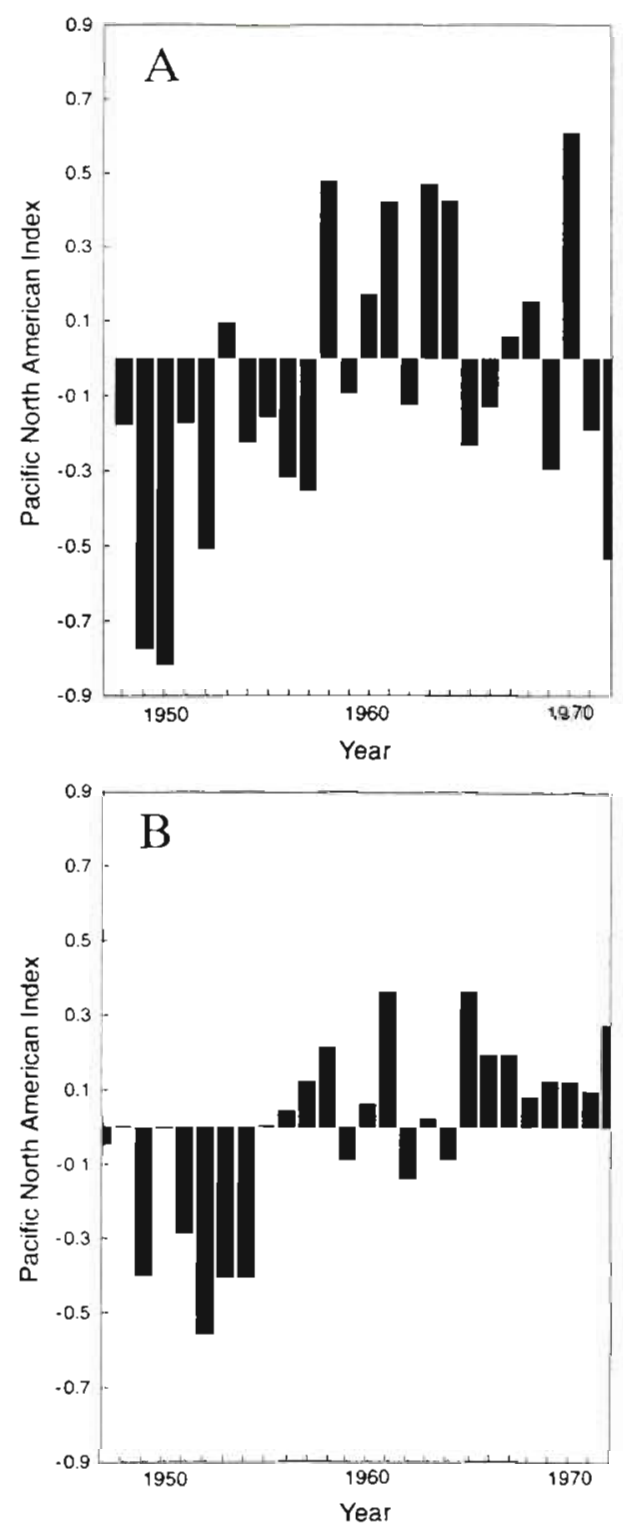

Fig. 8. Mean Pacific North American (PNA) index for (A) winters, and (B) summers, for the years 1947 through 1972

A change in atmospheric circulation over North America during the mid- to late 1950s has been identified by other studies as well. For example, Namias (1970), Kalnicky (1974), Dickson \& Namias (1976), Namias (1978), Balling \& Lawson (1982), Skeeter \& Parker (1985), Kalnicky, (1987), and Yarnal \& Leathers (1988) discuss a dramatic change in atmospheric circulation over North America from more zonal flow before the mid-1950s to more meridional flow after the mid1950s. Leathers \& Palecki (1992) found that differences in the PNA index before and after 1958 are statistically significant at the $99 \%$ confidence level. Studies that have focused on changes in atmospheric circulation in the Northern Hemisphere as a whole have also indicated a significant shift in circulation during the mid1950s to mid-1960s (Barnett \& Preisendorfer 1978, Jones et al. 1982, Angell \& Korshover 1983, Knox et al. 1988, Shabbar et al. 1990).

Numerous studies have indicated significant relations between changes in atmospheric circulation and surface temperature (Kalnicky 1974, Dickson \& Namias 1976, van Loon \& Williams 1976, Namias 1983, Skeeter \& Parker 1985, Kalnicky 1987, Trenberth 1990, Leathers \& Palecki 1992). For example, Namias (1983) discusses the relation between higher-than-average temperatures during the 'dust bowl' period of the late 1920 s and early to mid-1930s and the occurrence of anomalous anticyclonic circulation over the central United States. Leathers \& Palecki (1992) discuss the association between the shift in the PNA index from primarily negative values before the mid-1950s to primarily positive values after the mid-1950s and a decrease in temperature in the southeastern United States. Namias (1978) also discusses a significant discontinuity in winter temperatures in the southeastern United States after the mid-1950s. In addition, Dickson \& Namias (1976) discuss the sudden change in atmospheric circulation over North America during the mid1950s, and noted that the changes in atmospheric circulation tended to increase cyclogenesis along the east coast of the United States and to promote colder winters over the eastern half of the United States. Trenberth (1990) has indicated that increases in surface temperatures in Alaska and decreases over the North Pacific Ocean during the decade prior to 1988 were associated with changes in atmospheric circulation.

\section{CONCLUSIONS}

Seasonal and annual mean temperatures for the period from January 1895 through August 1989 for the 344 climate divisions in the conterminous United States were analyzed using the Lepage test. The results indicate that abrupt and significant changes in annual and seasonal temperatures occurred near 1930 and 1958, and that these changes occurred in a large part of the conterminous United States. The significant changes in temperatures near 1930 were primarily increases in annual and summer temperatures in the north-central and northeastern United States. In contrast, the significant changes in temperatures near 1958 were primarily decreases in annual, winter, and summer temperatures in the eastern United States Other significant and abrupt changes in seasonal temperatures occurred during the summer near 1917 and 1943, and during the autumn near 1948 and 1964 Overall, temperatures during the summer season 
exhibited the most frequent and widespread significant changes. In addition, the significant changes in annual and seasonal temperatures occurred over large areas and were associated with changes in atmospheric circulation.

The results of this study indicate 4 important points with implications for the development of scenarios of future climatic conditions: (1) climatic change does not appear to occur as a gradual change, but rather occurs as abrupt changes, as suggested by Lorenz (1968, 1976); (2) the most widespread and frequent changes in seasonal temperatures during the last century in the conterminous United States have been during the summer seasons; (3) significant temperature changes occur over large areas; and (4) the abrupt changes in climate are associated with changes in atmospheric circulation.

\section{LITERATURE CITED}

Angell, J. K., Korshover, J. (1983). Global temperature variations in the troposphere and stratosphere, 1985-1982. Mon. Weather Rev. 111: 901-921

Balling, R. C., Idso, S. B. (1989). Historical temperature trends in the United States and the effect of urban population growth. J. geophys. Res. 94: 3359-3363

Balling, R. C., Lawson, M. P. (1982). Twentieth-century changes in winter climatic regions. Clim. Change 4:57-69

Barnett, T P., Preisendorfer, R. W. (1978). Multifield analog prediction of short-term climate fluctuations using a climate state vector. J atmos. Sci. 35: 1771-1787

Barnston, A. G., Livezy, R. E. (1987). Classification, seasonality and persistence of low-frequency atmospheric circulation patterns. Mon. Weather Rev. 115: 1083-1126

Blackmon, M. L., Lee, T.-H, Wallace, J. M. (1984). Horizontal structure of $500 \mathrm{mb}$ height fluctuations with long, intermediate and short time scales. J. atmos. Sci. 41: 1961-1979

Demaree, G. R., Nicolis, C. (1990). Onset of Sahelian drought viewed as a fluctuation-induced transition. Q. J. R. Meteorol. Soc. 116: 221-238

Dettinger, M. D., Ghil, M. (1992). Interannual and interdecadal variability of surface-air temperatures in the United States. In: Proceedings 16 th Annual Climate Diagnostics Workshop, University of California, Los Angeles. NOAA, U.S. Dept of Commerce, Washington. DC, p. $209-214$

Diaz, H. F., Quayle, R. G. (1980). The climate of the United States since 1895: spatial and temporal changes. Mon Weather Rev. 108: 249-266

Dickson, R. R., Namias, J. (1976). North American influences on the circulation and climate of the North Atlantic sector. Mon. Weather Rev. 104: 1255-1265

Ghil, M., Vautard, R. (1.991). Interdecadal oscillations and the warming trend in global temperature time series. Nature 350: $324-327$

Gleick, P. H. (1987). Regional hydrologic consequences of increases in atmospheric $\mathrm{CO}_{2}$ and other trace gases. Clim. Change 10: 137-161

Hirakawa, K. (1974). The comparison of powers of distribution-tree sample test. TRU Mathematics 10: 65-82

Intergovernmental Panel on Climate Change (1990). Climate change: the IPCC scientific assessment. Cambridge University Press, New York
Intergovernmental Panel on Climate Change (1992). Climate change: the supplementary report to the IPCC scientific assessment. Cambridge University Press, New York

Jones, P. D., Wigley, T. M. L., Kelly, P. M. (1982). Variations in surface air temperatures: Part 1. Northern Hemisphere, 1881-1980. Mon. Weather Rev. 110: 59-70

Jones, P. D., Raper, S. C. B., Bradley, R. S., Diaz, H. F., Kelly, P. M. Wigley, T M. L. (1986). Northern Hemisphere surface air temperature variations: 1851-1984. J. Clim. appl. Meteorol. 25: 161-179

KaInicky, R. A. (1974). Climatic change since 1950. Ann. Ass. Am. Geograph. 64: 100-112

Kalnicky, R. A. (1987). Seasons, singularities, and climatic changes over the midlatitudes of the Northern Hemisphere 1899-1969. J. Clim. appl. Meteorol. 26: $1496-1510$

Karl, T. R., Riebsame, W. E. (1.984). The identification of 10- to 20 -year temperature and precipitation fluctuations in the contiguous United States. J. Clim. appl. Meteorol. 23: 950-966

Karl, T R., Rjebsame, W. E. (1989). The impact of decadal fluctuations in mean precipitation and temperature on runoff: a sensitivity study over the United States. Clim. Change 15: 423-447

Karl, T R., Williams, C. N. Jr, Young, P. J., Wendland, W. M. (1986). A model to estimate the time of observation bias associated with monthly mean maximum, minimum and mean temperatures for the United States. J. Clim. appl. Meteorol. 25: 145-160

Knox, J. L., Higuchi, K., Shabbar, A., Sargent, N. E. (1988). Secular variations of Northern Hemisphere $50 \mathrm{kPa}$ geopotential height. J. Climate 1: 500-511

Leathers, D. J., Palecki, M. A. (1992). The Pacific/North American teleconnection pattern and the United States climate. Part II. Temporal characteristics and Index specification. J. Climate 5: 707-716

Leathers, D. J., Yarnal, B., Palecki, M. A. (1991). The Pacific/ North American teleconnection pattern and United States climate. Part 1: regional temperature and precipitation associations. J. Climate 4:517-528

Lepage, Y. (1971). A combination of Wilcoxon's and AnsariBradley's statistics. Biometrika 58: 213-217

Lins, H. F., Sundquist, E. T., Ager, T. A. (1988). Information on selected climate and climate-change issues. U. S. Geologi.cal Survey Open-File Report 88-718, Reston, Virginia

Lorenz, E. N. (1968). Climate determinism. Meteorol. Monogr. 8: $1-3$

Lorenz, E. N. (1976). Nondeterministic theories of climatic change. Quat. Res. 6: 495-506

McCabe, G. J., Wolock, D. W. (1992). Effects of climatic change and climatic variability on the Thornthwalte moisture index in the Delaware River basin. Clim. Change 20: $143-153$

McGuirk, J. A. (1982). A century of precipitation variability along the Pacific Coast of North America and its impact. Clim. Change 4: 41-56

Namias, J. (1970). Climate anomaly over the United States during the 1960s. Science 170: 741

Namias, J. (1978). Multiple causes of the North American abnormal winter 1976-77 Mon. Weather Rev, 106: $279-295$

Namias, J. (1983). Some causes of United States drought. J. Climate appl. Meteorol. 22: 30-39

Plantico, M. S., Karl, T R. Kukla, G., Gavin, J. (1990) Is recent climate change across the United States related to rising levels of anthropogenic greenhouse gases? J. geophys. Res. 95: 16617-16637 
Potter, K. W. (1981). Illustration of a new test for detecting a shift in mean precipitation series. Mon. Weather Rev. 109 2040-2045

Pittock, A. B. (1983), Recent climatic change in Australia: implications for a $\mathrm{CO}_{2}$-warmed Earth. Clim. Change 5 . $321-340$

Schlesinger, M. E. (1989). Model projections of the climatic changes induced by increased atmospheric $\mathrm{CO}_{2}$. In Berger, A., Schneider, S., Duplessy, J. C. (eds.) Climate and the geosciences: a challenge for science and society in the 21st century. Kluwer Academic Publishers, Dordrecht, p. $375-415$

Shabbar, A., Higuchi, K., Knox, J. L. (1990). Regional analysis of Northern Hemisphere $50 \mathrm{kPa}$ geopotential heights from 1946 to 1985 . J. Climate 3: 543-557

Simmons, A. J., Wallace, J. M., Branstator, G. W. (1983). Barotropic wave propagation and instability, and atmospheric teleconnection patterns. J. atmos. Sci. 40: 1363-1392

Skeeter, B. R., Parker, A. J. (1985). Synoptic control of regional temperature trends in the conterminous United States between 1949 and 1981. Phys. Geogr. 6: 69-84

Solow, A. R. (1987). Testing for climate change: an application of the two-phase regression model. J. Climate appl. Meteorol. 26: 1401-1405

Solow, A. R., Broadus, J. M. (1989). On the detection of green-

Editor: V. Meentemeyer, Athens, Georgia, USA house warming. Clim. Change 15: 449-453

Trenberth, K. E. (1990). Recent observed interdecadal climate changes in the Northern Hemisphere. Bull. Am. Meteorol. Soc. 71: 988-993

van Loon, H., Williams, J. (1976). The connection between trends of mean temperature and circulation at the surface: Part I. Winter. Mon. Weather Rev. 104: 365-380

Wallace, J. M., Gutzler, D. S. (1981). Teleconnections in the $500 \mathrm{mb}$ geopotential height field during the Northern Hemisphere winter. Mon. Weather Rev. 109: 784-812

Yamamoto, T., Iwashima, T., Sanga, N. K., Hoshiai, M. (1986). An analysis of climatic jump. $\int$. meteorol. Soc. Japan 70 : $95-104$

Yonetani. T. (1992). Discontinuous climate changes in Japan after 1900. J. meteorol. Soc. Japan 70: 1125-1135

Yonetani, T. (1993). Detections of long term trend, cyclic variation and step like change by the Lepage test. J. meteorol. Soc. Japan 71: 415-418

Yarnal, B., Diaz, H. F. (1986). Relationships between extremes of the Southern Oscillation and the winter climate of the Anglo-American Pacific coast. J. Climatol. 6: 197-219

Yarnal, B., Leathers, D. J. (1988). Relationships between interdecadal and interannual climatic variations and their effect on Pennsylvania climate. Ann. Ass. Am. Geograph. 78: $624-641$

Manuscript first received: August 21, 1993

Revised version accepted: February 28, 1994 